Meta

Journal des traducteurs

Translators' Journal

\title{
L'École de traducteurs et d'interprètes de Beyrouth : vivre une guerre ou traduire sur les lignes de démarcation
}

\section{Henri Awaiss}

Volume 60, numéro 2, août 2015

$60^{\mathrm{e}}$ anniversaire. Les horizons de la traduction : retour vers le futur $60^{\text {th }}$ Anniversary. Translation's Horizons: Back to the Future

60mo aniversario. Los horizontes de la traducción: regreso al futuro

URI : https://id.erudit.org/iderudit/1032862ar

DOI : https://doi.org/10.7202/1032862ar

Aller au sommaire du numéro

Éditeur(s)

Les Presses de l’Université de Montréal

ISSN

0026-0452 (imprimé)

1492-1421 (numérique)

Découvrir la revue

Citer ce document

Awaiss, H. (2015). L'École de traducteurs et d'interprètes de Beyrouth : vivre une guerre ou traduire sur les lignes de démarcation. Meta, 60(2), 311-311.

https://doi.org/10.7202/1032862ar d'utilisation que vous pouvez consulter en ligne. 


\title{
L'École de traducteurs et d'interprètes de Beyrouth: vivre une guerre ou traduire sur les lignes de démarcation
}

\author{
Henri Awaiss \\ Université Saint-Joseph, Beyrouth, Liban \\ hawaiss@usj.edu.lb
}

C’était en 1980 quand deux jésuites français, assistés de deux professeurs libanais, ont compris l'étroite relation entre leur lieu de travail, en l'occurrence l'Université SaintJoseph devenue ligne de démarcation, et la traduction. En effet, cette belle discipline a toujours vécu sur les frontières entre deux langues, ou, mieux encore, elle s'est trouvée prête à fonctionner en médiation entre un auteur et un nouveau lecteur. Très fiers de cette correspondance, les quatre ont œuvré à la mise en place d'un programme sur cinq ans, trois de licence, deux de diplôme pour la formation en traduction et en interprétation des jeunes Libanais rongés par l'insécurité et la violence.

Désormais, la traduction, en tant que discipline indépendante ayant ses spécificités, faisait son entrée magistrale pour la première fois à l'Université au Liban, pays où le choix des langues reflète souvent avec des options confessionnelles et politiques. Au début, les gens croyaient que ce programme ne comportait pas assez de langues car pour eux tout le monde était trilingue, sans se soucier de la différence entre connaître quelques expressions, en claquer d'autres et s'exprimer couramment à l'écrit et à l'oral, passer d'un système à l'autre.

Les défis furent énormes. Mais, 35 ans après, le programme a fait ses preuves. Une dizaine d'autres programmes similaires a vu le jour. Le Liban, terre à maintes reprises brûlée, serait-il terre d'accueil si fertile à la traduction, acte sublime de toute communication?

Directeur de l'Institut de langues et de traduction et de l'École de traducteurs et d'interprètes de Beyrouth (1996-2012), Henri Awaiss est actuellement Doyen de la Faculté des langues. Ses quatre domaines d'activité sont: l'enseignement, la recherche dans deux domaines, à savoir, la traductologie et l'élaboration de matériels d'arabe, la formation à travers des stages et des séminaires, et l'édition, notamment les deux collections: sources-cibles, spécialisée en traductologie, et Al-Lissane, spécialisée en langues ainsi que les Annales: Al Kimiya et Portalingua. II a récemment dirigé avec Jarjoura Hardane la publication dans la collection Sources-Cibles d'une trilogie de réflexions collectives sur les langues et la traduction: Mes deux amours (2009), Les liaisons dangereuses (2011), Jamais l'un sans l'autre (2013); ainsi que, dans la collection Al-Lissane, Arabe et Compagnie (2013-2014) et Portalingua (2014-2015). 